\title{
Política de la República Federal de Alemania hacia España durante el franquismo y la transición (1949-1979)*
}

\author{
The Federal Republic of Germany Policy towards Spain during \\ Francoism and the Transition to Democracy (1949-1979)
}

\author{
Natalia Urigüen López de Sandaliano \\ Universidad Nacional de Educación a Distancia (UNED), Madrid
}

Recibido: 27-III-2014

Aceptado:21-VII-2014

\section{Resumen}

En este artículo se realiza un análisis de la evolución de la política que la República Federal de Alemania (RFA) desarrolló hacia España durante las tres décadas que separan la creación del joven Estado federal y la entrada en vigor de la Constitución Española. Sin tratar de abarcar todos y cada uno de los asuntos que la caracterizaron, se pretende estudiar la conformación de los grandes vectores que la articularon y su paulatina transformación, en sintonía con la evolución internacional y la de ambos países.

Palabras clave: "Tradicional Amistad", Democracia Cristiana, CDU, SPD, Equipo Demócrata Cristiano del Estado Español, Fundación Konrad Adenauer, UCD, Fundación Friedrich Ebert, Fundación Hanns Seidel, Fundación Friedrich Naumann.

\begin{abstract}
In this article we analyse the development of the of the German Federal Republic policy towards Spain during the three decades that separate the creation of the young federal State and the establishment of the new Spanish Constitution. Rather than covering all the issues that characterised that period, we will try to study the formation of those large vectors that articulated that relationship and its gradual transformation, in line with international evolution and also with the evolution of both countries.
\end{abstract}

* Este artículo forma parte del trabajo de investigación de la autora para la presentación de la tesis doctoral titulada: "El papel de la democracia cristiana alemana en la transición española". 
Keywords: "Traditional Friendship", Christian Democracy, CDU, SPD, Equipo "Demócrata Cristiano del Estado Español", Konrad Adenauer Foundation, UCD, Friedrich Ebert Foundation, Hanns Seidel Foundation, Friedrich Naumann Foundation.

\section{Introducción}

Las relaciones entre España y la República Federal de Alemania (RFA), desde la creación de ésta última en 1949, tuvieron una evolución peculiar debido al fuerte condicionamiento impuesto por el contexto internacional de la Guerra Fría, pero sobre todo por la diferencia estructural existente entre un nuevo estado democrático alemán con pretensiones de ejemplaridad y una de las últimas dictaduras del continente, a su vez sometida al aislamiento internacional. Pasaron varios años antes de que la "tradicional amistad", que tanto daño había hecho a los ojos de los aliados durante la Guerra Civil española y la Segunda Guerra Mundial, se restableciera y consolidara. La relación entre ambos países, si bien es cierto que benefició al régimen franquista, fue también importante como impulsora de los esenciales cambios sociopolíticos que llevarían a España a convertirse en los años setenta en una democracia. Desde antes de la muerte de Franco en noviembre de 1975, es destacable la implicación de la RFA en el proceso de transición española, materializándose en la ayuda e interlocución a diferentes niveles, desde el gubernamental hasta el de partidos y el de fundaciones políticas.

\section{Las relaciones hispano-alemanas durante los primeros años de postguerra mundial}

Durante los primeros cuatro años de postguerra, los países aliados ocupantes del territorio que a continuación conformó la RFA no permitieron las relaciones bilaterales hispano-alemanas. España pagaba así las consecuencias de ser una de las dictaduras que aún perduraban en el continente europeo y, por encima de ello, el que Franco hubiera mantenido su amistad con Hitler hasta prácticamente el final de la guerra. De hecho, España llevó a cabo una política acomodaticia respecto al conflicto bélico. Si en sus inicios se declaró neutral, en junio de 1940 cambiaba su status oficial al de "no beligerancia", para volver a la neutralidad a finales de 1943, cuando comenzaba a perfilarse la victoria de los aliados. En cualquier caso, la postura de España favoreció a los países del Eje. Suministró a Alemania wolframio, materia prima muy codiciada en los momentos de guerra. Puso a disposición de Hitler una división de voluntarios, la llamada División Azul, para luchar en el frente ruso al lado de la Wehrmacht 
contra el comunismo. Permitió que la Gestapo y otros servicios secretos alemanes se instalaran en la Península y el Protectorado de Marruecos, y a su vez acogió a numerosos ciudadanos alemanes que se establecieron en España ${ }^{1}$.

La resolución 39(I) de Naciones Unidas (febrero de 1946) llevó al bloque occidental a congelar las relaciones diplomáticas con España, hasta el punto de cerrar Francia la frontera pirenaica. España quedó aislada, siendo considerado el régimen franquista como una amenaza para la paz y seguridad internacional ${ }^{2}$.

Por su parte, Alemania quedó dividida en cuatro partes y sometida al Consejo Aliado de Control, careciendo de soberanía durante los primeros años de postguerra y por lo tanto de una política exterior propia. En consecuencia, las relaciones hispano-alemanas entre 1945 y 1949 fueron en realidad las relaciones entre España y los tres países ocupantes del territorio alemán occidental, es decir, Estados Unidos, Francia e Inglaterra. La prioridad de éstos fue acabar con cualquier posible vestigio de nacionalsocialismo en territorio español a través del programa Safehaven, implementado en 1944 y por el cual los aliados perseguían cuatro objetivos: eliminar la ayuda indirecta que los países neutrales seguían proporcionando a Alemania mediante relaciones comerciales y financieras; inmovilizar todos los activos e inversiones alemanas en estos países, incluyendo materias primas, mercancías elaboradas, depósitos bancarios, etc.; impedir la fuga de bienes y capitales de nacionalsocialistas; y finalmente restituir los bienes robados a sus dueños legítimos ${ }^{3}$. En paralelo, los aliados comenzaron a exigir el desmantelamiento de la red de espionaje alemán que se había constituido en España y la expulsión de una larga lista de ciudadanos alemanes.

Tanto para Alemania como para España, el factor decisivo que contribuyó al cambio de situación fue el inicio de la Guerra Fría. La escalada de rivalidad, que se había ido produciendo entre Estados Unidos y la Unión Soviética hasta 1947, llevó a las potencias occidentales a sustituir su ideología antifascista por un férreo anticomunismo. Este cambio forzado permitió reinsertar a España y la RFA en el nuevo orden internacional.

1. COLLADO, Carlos, "España y los agentes alemanes 1944-1947. Intransigencia y pragmatismo político", Espacio, Tiempo y Forma, Serie V, Historia Contemporánea, no 5 (1992), pp. 431-482; MORENo, Xavier, La División Azul: Sangre española en Rusia, 1941-1945, Barcelona, Crítica, 2006; viÑAs, Ángel, Franco, Hitler y el estallido de la Guerra Civil. Antecedentes y consecuencias, Madrid, Alianza Editorial, 2001.

2. Sobre el aislamiento del régimen franquista en los primeros años de postguerra véase PORTERO, Florentino, Franco aislado. La cuestión española (1945-1950), Madrid, Aguilar, 1989.

3. Sobre el programa Safehaven véase Collado, Carlos, Angst vor dem "Vierten Reich". Die Alliierten und die Ausschaltung des deutschen Einflusses in Spanien, 1944-1958, Paderborn, Schöningh, 2001; COllado, C., España, refugio nazi, Madrid, Temas de hoy, 2005. 


\section{La reconstrucción de la tradicional amistad durante los años cincuenta}

España, relegada en el escenario internacional con su posición periférica dentro del continente europeo y con una economía muy atrasada, ocupó un puesto secundario en la política exterior de la RFA en los años cincuenta, al no poder contribuir a ninguno de los asuntos que preocuparon a ésta en aquella época: el restablecimiento de su soberanía, la unificación de ambas Alemanias y la construcción de la Comunidad Europea ${ }^{4}$. De las cuestiones fundamentales para la RFA sólo una afectaba también a España: reforzar la defensa de Europa occidental contra la amenaza soviética.

Las relaciones entre ambos países comenzaron a restablecerse a partir de 1949. La RFA valoró muy positivamente el respeto por parte del gobierno español a la doctrina Hallstein ${ }^{5}$. También tuvo muy en cuenta el apoyo invariable de su "tradicional amigo" a la postura de Bonn en la "cuestión alemana" dentro de los círculos internacionales y en concreto, desde 1955, en la Organización de Naciones Unidas, a la cual la RFA no pertenecía.

Tres ideas básicas constituyeron el punto de partida de la política exterior de la joven RFA hacia el régimen de Franco y se mantuvieron constantes hasta la desaparición de éste: la no injerencia en los asuntos internos del país, dejando de lado la naturaleza antidemocrática del franquismo; la necesidad de olvidar viejos resentimientos de la época de la Segunda Guerra Mundial y la postguerra; y el apoyo a la integración de España en la OTAN y la Comunidad Económica Europea (CEE). A través de esta última idea el gobierno federal buscó favorecer el incremento de las relaciones económicas bilaterales, promover la estabilidad social y política en España, así como fomentar la evolución y liberalización del régimen ${ }^{6}$.

4. Sobre los pilares fundamentales sustentadores y los objetivos perseguidos por la política exterior de la RFA a partir de 1949 véase HANRIEDER, Wolfram F., Germany, America, Europe: Forty Years of German Foreign Policy, Yale, Yale University, 1989; LAPPENKÜPER, Ulrich, Die Außenpolitik der Bundesrepublik Deutschland 1949 bis 1990, Munich, Oldenburg, 2008; PFETSCH, Frank R., Die Außenpolitik der Bundesrepublik Deutschland von Adenauer zu Merkel, Schwalbach, Wochenschau Verlag, 2011; SCHÖLlGEN, Gregor, Die Außenpolitik der Bundesrepublik Deutschland. Von den Anfängen bis zum Gegenwart, Munich, Beck, 1999.

5. Según la doctrina Hallstein, enunciada en 1955, la RFA era el único país con derecho a representar internacionalmente al pueblo alemán y por lo tanto se consideraría el establecimiento de relaciones de cualquier país con la República Democrática de Alemania (RDA) como un acto hostil de ese país hacia la RFA.

6. Sobre las relaciones bilaterales entre ambos países durante los gobiernos demócrata cristianos de Konrad Adenauer y Ludwig Erhard véase ASCHMAnN, Birgit, "Treue Freunde..."? Westdeutschland und Spanien 1945-1963, Stuttgart, Franz Steiner Verlag, 1999; LEHMANN, Walter, Die Bundesrepublik und Franco-Spanien in den 50er Jahren, Munich, Oldenburg 
El carácter dictatorial del franquismo y su anterior vinculación con el nacionalsocialismo no jugaron un papel relevante en las relaciones bilaterales durante los gobiernos de Konrad Adenauer, dando Bonn mayor importancia a otro tipo de valores comunes de los dos países como fueron el anticomunismo y el cristianismo. Debido a la limitada capacidad de acción exterior, la elección de sus prioridades y la prudencia política, el gobierno alemán no tuvo excesiva prisa en reiniciar sus relaciones directas con el régimen franquista. Mientras que España contaba ya con una embajada en Bonn desde la primavera de 1951, hasta 1952 no se estableció la primera embajada de la RFA en Madrid, a la que siguieron en los años siguientes una serie de consulados en diferentes ciudades españolas. El mayor problema alemán fue encontrar un perfil adecuado para sus representantes diplomáticos en España, ya que el gobierno federal quiso evitar cualquier posible vinculación anterior de sus candidatos con el nacionalsocialismo ${ }^{7}$.

Durante los primeros años de existencia de la RFA, los objetivos de la política exterior de Adenauer hacia España fueron: el restablecimiento de relaciones diplomáticas, la defensa de los intereses comerciales alemanes en territorio español y la prestación de asistencia consular a los miles de ciudadanos alemanes que residían en España. A estas tres metas hay que añadir una cuarta a la que Bonn dio gran importancia: la recuperación por parte alemana de las propiedades del Tercer Reich en España, propiedades que el régimen se había estado apropiando desde 1945 aprovechando la cobertura que le otorgaba el programa Safehaven de los aliados. Alemania occidental, en pleno proceso de reconstrucción moral, política y económica, dio con ello los primeros pasos, bajo vigilancia aliada, hacia el restablecimiento de unas relaciones "nuevas", libres de toda carga del pasado.

La RFA decidió apoyar a España en sus esfuerzos por salir del aislamiento internacional, siendo su objetivo principal el refuerzo del bloque occidental. Bonn valoraba tanto el anticomunismo de España y el uso que podía hacerse

Verlag, 2006; NIEHus, Gerlinde Freia, Außenpolitik im Wandel. Die Außenpolitik Spaniens von der Diktatur Francos zur parlamentarischen Demokratie, Frankfurt, Vervuert, 1989; SANZ, Carlos, España y la República Federal de Alemania (1949-1966): Política, Economía y Emigración entre la Guerra Fría y la distensión, tesis doctoral inédita. Universidad Complutense de Madrid, 2005; WEBER, Petra Maria, Spanische Deutschlandpolitik 1945-1958. Entsorgung der Vergangenheit?, Frankfurt, Verlag Breitenbach, 1992.

7. Los acuerdos de Petersberg, que permitían a la RFA establecer relaciones diplomáticas y comerciales con los países occidentales, se habían firmado en noviembre de 1949, pero España no estaba en la lista de prioridades establecida por los aliados. Sobre el establecimiento de las primeras embajadas en sendos países véase ASCHMAnN, Birgit, "Treue Freunde..."?..., pp. 201-223. 
de éste, como su posición estratégica. El gobierno federal siguió muy de cerca los convenios defensivos firmados entre España y Estados Unidos en 1953, por los cuales se autorizaba el establecimiento de bases americanas en suelo español. Igualmente, la visión alemana del aspecto geoestratégico de España le llevó, desde su propio ingreso en la OTAN en 1955, a apoyar de una u otra manera la admisión española. Sin embargo, durante los años en que Konrad Adenauer estuvo al frente de la Cancillería, un apoyo demasiado explícito al régimen franquista aún constituyó un tema polémico. A nivel nacional, los socialdemócratas alemanes en la oposición se oponían a la entrada de España en la OTAN. En el ámbito internacional, un intento de cooperación militar bilateral fuera de la Alianza Atlántica y de la Unión Europea Occidental chocaba con la oposición frontal de Estados Unidos, Francia, Gran Bretaña y otros países occidentales, como pudo comprobarse con el intento fallido de establecer unas bases militares alemanas en España en 1960'.

Junto al cauce oficial en las relaciones bilaterales entre ambos gobiernos existió también una paradiplomacia extraoficial, desarrollada a través de instituciones como el Centro Europeo de Documentación e Información (CEDI) o el Comité Internacional para la Defensa de la Civilización Cristiana (CIDCC), entre otros ${ }^{9}$. El CEDI fue una asociación privada fundada en 1952 por personalidades destacadas de la vida pública española. Su creación buscaba una unión bajo el signo de un movimiento cristiano europeo, con el objetivo de superar el aislamiento al que se veía sometida la élite franquista ${ }^{10}$. A través del

8. Respecto a los intentos de cooperación bilateral entre ambos Estados y el intento fallido de establecer depósitos militares en España véase Collado, Carlos, "Planes militares de Adenauer en España", Espacio Tiempo y Forma. Serie V, Historia Contemporánea, $\mathrm{n}^{\circ} 4$ (1991), pp. 97-116; COLLADO, C., "El proyecto de las bases militares alemanas en España", BERNECKER, Walter (ed.), España y Alemania en la Edad Contemporánea, Frankfurt, Vervuert Verlag, 1992, pp. 231-255.

9. Para más información sobre el CEDI véase ASChMAnN, Birgit, "Treue Freunde...”?..., pp. 425-435; AschmanN, B., "La República Federal de Alemania y la imagen de Alemania en España, 1945-1963", Ayer. Revista de Historia Contemporánea no 69 (2008), pp. 129-154; BENEYTO, Juan, "Las asociaciones de Amistad durante el franquismo", Revista de Estudios Políticos (Nueva Época), no 71, enero-marzo 1991, pp. 210-212; GROSSMANn, Johannes, Die Internationale der Konservative. Transnationale Elitenzirkel und private Aussenpolitik in Westeuropa seit 1945, Munich, Oldenburg Verlag, 2014; MORENO, Antonio, "El Centro Europeo de Documentación e Información. Un intento fallido de aproximación a Europa, 1952-1962", tusell, Javier et alii (eds.), El régimen de Franco (1936-1975), Madrid, UNED, 1993, pp. 459-474; wEBER, Petra Maria, "El CEDI: promotor del Occidente cristiano y de las relaciones hispano-alemanas de los años cincuenta", Hispania, LIV/3, $\mathrm{n}^{\circ} 188$ (1994), pp. 1077-1103; WEBER, P. M., Spanische Deutschlandpolitik 1945-1958. Entsorgung der Vergangenheit, Breitenbach, Saarbrücken Lauderdale, 1992, pp. 205-268. Sobre el CIDCC véase fundamentalmente BENEYTO, Juan, "Las asociaciones de Amistad durante el franquismo"..., pp. 212-218; SANZ, Carlos, España y la República Federal de Alemania..., pp. 450-457.

10. WEBER, Petra Maria, "El CEDI: promotor del Occidente cristiano...", p. 1078. 
CEDI se crearon vías de comunicación entre determinadas personalidades políticas españolas de ideología nacionalcatólica (Alfredo Sánchez Bella, Alberto Martín Artajo y José Ignacio Escobar, entre otros) y círculos católicos de Baviera identificados con la Abendländische Aktión (de inspiración católica y occidental "Abendland"). Los miembros de ambas asociaciones coincidían durante los años cincuenta en las reuniones que se celebraban en El Valle de los Caídos o en El Escorial por parte del CEDI y en la Abendländische Akademie en Eichenstatt por parte alemana. Hanns Seidel (ministro-presidente de Baviera), Heinrich von Brentano (ministro de Exteriores), diversos presidentes de los Länder, Franz Josef Strauss (por aquel entonces Ministro de Energía Atómica), varios diputados del Bundestag, incluido su vicepresidente Richard Jaeger, periodistas, obispos y aristócratas bávaros, etc., se encontraban entre los asiduos que asistían a los encuentros organizados por ambos foros. Se establecieron así contactos entre personalidades de una misma visión cristiana, conservadora y "occidentalista". El Auswärtiges Amt, nunca apoyó oficialmente las actividades del CEDI, sin embargo supo aprovechar los contactos que se establecían a través de las reuniones que se celebraban anualmente. Los utilizó como canales de comunicación extraoficial con el gobierno español y a la vez para hacer propaganda en el exterior de su posicionamiento en asuntos como la división de Alemania, la situación de Berlín o las perspectivas de reunificación. A Adenauer le llegaba la información que por parte alemana se recogía en los congresos. Una vez que en los años sesenta se normalizaron los cauces oficiales entre la RFA y España, el valor del CEDI como vía de comunicación disminuyó ${ }^{11}$.

El CIDCC fue otro foro de diplomacia paralela que permitió estrechar las relaciones entre el régimen franquista y la RFA en los años cincuenta y sesenta. A esta institución pertenecieron José Solís, Manuel Fraga y el general Muñoz Grandes, entre otros. Nació de una iniciativa italiana, pero su base fue siempre alemana. Ligado a la democracia cristiana a nivel internacional, mientras ésta se mantuvo en el poder en la RFA, el CIDCC fue subvencionado en parte por el gobierno alemán. Organizaba cursos, conferencias y comunicaciones con contenido político, cultural y propagandístico de ideología conservadora y anticomunista $^{12}$.

Otro de los aspectos en los que la RFA fue importante para España es el ámbito económico, aunque en un principio las relaciones estuvieron marcadas por la incertidumbre. Inicialmente fueron EEUU, Reino Unido y Francia, a través del Consejo Aliado de Control, los que reabrieron los cauces comerciales

11. SANZ, Carlos, España y la República Federal de Alemania..., pp. 434-450.

12. BENEYTO, Juan, "Las asociaciones de Amistad durante el franquismo"..., pp. 212-213. 
con España mediante un convenio firmado entre Madrid y la Trizona a finales de 1948. Sin embargo, la situación de partida era totalmente contraria entre ambos países: España sometida a la autarquía, que se tradujo en el retraso del crecimiento económico del país durante toda la década de los años cincuenta; la RFA integrada en el capitalismo internacional, desarrollando una espectacular reconstrucción desde 1948, cuyo motor de arranque fue la ayuda del Plan Marshall, de la que España había sido excluida. Alemania occidental siguió la vía del multilateralismo en sus relaciones económicas exteriores, mientras que España no tuvo más opción que seguir la vía bilateral. El gobierno español cambió de táctica a raíz de los Tratados de Roma, pero hasta entonces transcurrió una década de estancamiento. La RFA fue un proveedor de productos y maquinaria absolutamente necesarios para la industrialización del país, mientras que Alemania occidental veía en España un proveedor de productos alimenticios esenciales y de materias primas necesarias para su reconstrucción. Bonn alcanzó hacia 1952 el primer objetivo que se había propuesto, la recuperación de su puesto en el mercado español, terreno que había perdido ante la competencia francesa, británica y estadounidense $e^{13}$.

Si bien en un principio el gobierno de la RFA consiguió el despegue de las relaciones comerciales entre ambos países, pronto surgieron los obstáculos derivados del escaso grado de apertura económica española y de la no pertenencia a ninguna organización de carácter multilateral. La realidad era que España incumplía las condiciones comerciales acordadas, a lo que se sumaban problemas de liquidez. Al gobierno alemán no le quedó más remedio que hacer concesiones para no perder las relaciones comerciales entre ambos países. A mediados de los años cincuenta, la RFA rediseñó su política económica hacia España, con el objetivo de que a corto plazo el gobierno español cumpliera con las condiciones establecidas en cuanto a volumen, plazos, licencias, etc., y de estimular el aumento de las exportaciones españolas a Alemania occidental. A medio plazo Bonn había decidido apoyar el ingreso de España en la Organización Europea para la Cooperación Económica y la Unión Europea de Pagos. Básicamente suponía fomentar la apertura y liberalización de la economía española, lo cual beneficiaba a los intereses exportadores alemanes ${ }^{14}$.

13. Sobre las inversiones extranjeras en España véase BARCIELA, Carlos et alii (coords.), La España de Franco (1939-1975). Economía, Madrid, Síntesis, 2001, pp. 233-238.

14. SAnz, Carlos, España y la República Federal de Alemania..., pp. 271 y 275; ASCHMAnN, Birgit, "Treue Freunde..."?..., pp. 286-311; Aschmann, B., "The Reliable Ally: Germany Supports Spain's European Integration Efforts, 1957-1967", Journal of European Integration History, vol. 7, $\mathrm{n}^{\circ} 1$ (2007), pp. 37-51. 
En 1958, el problema entre la RFA y España sobre las propiedades alemanas incautadas en territorio español quedó solucionado con la firma de dos acuerdos entre ambos países: el Convenio sobre ciertos efectos de la Segunda Guerra Mundial entre España y la República Federal de Alemania y el Convenio para la rehabilitación de derechos de propiedad industrial entre España y la República Federal de Alemania ${ }^{15}$. El desenlace fue muy bien valorado por parte del gobierno federal, más por lo que significaba como restitución moral que por suponer una ganancia económica significativa. La resolución del contencioso, la entrada de ministros tecnócratas en el gobierno español y la aplicación del Plan Nacional de Estabilización Económica de 1959 contribuyeron a la intensificación de las relaciones bilaterales desde finales de los años cincuenta. Los cambios aperturistas por parte del régimen franquista se produjeron a raíz del tratado de Roma y ante el temor de un mayor aislamiento de la economía española en el ámbito europeo. El resultado fue la admisión de España en los organismos económicos internacionales, produciéndose a lo largo de los años sesenta una mayor liberalización económica ${ }^{16}$.

\section{La profundización de las relaciones bilaterales durante los años sesenta}

En los años sesenta, la RFA era ya una gran potencia económica occidental presente en la mayoría de los organismos técnicos internacionales. Además, se había convertido en un gran aliado para la defensa del bloque anticomunista. El riesgo de que los Estados Unidos dejaran de apoyar la política de Bonn respecto a la "cuestión alemana", así como el favorecimiento invariable del gobierno español a la doctrina Hallstein se tradujeron a lo largo de esta década en un mayor estímulo de la RFA a la inserción de España en el bloque occidental. El gobierno de Ludwig Erhard (1963-1966) mantuvo la continuidad política hacia el régimen de Franco, apoyando la aproximación de España a Europa, el desarrollo de su economía y la mejora de su situación en la escena internacional. Erhard no mostró durante su gobierno un especial interés por España; pero su visión de una "Europa de países libres e iguales", unida en estructuras de integración económicas más amplias que las existentes hasta el momento, incluía también a las dictaduras ibéricas, fundamentalmente por coherencia con su visión económica y librecambista. A diferencia de Adenauer, España y

15. Convenio sobre ciertos efectos de la Segunda Guerra Mundial entre España y la República Federal de Alemania y el Convenio para la rehabilitación de derechos de propiedad industrial entre España y la República Federal de Alemania, firmados el 8 de abril de 1958 en Madrid. Editados en Madrid, Ministerio de Asuntos Exteriores, 1959 (Registro de Tratados $\left.\mathrm{n}^{\circ} 119\right)$.

16. aschmann, Birgit, "Treue Freunde...”?..., pp. 258-259. 
Portugal jugaron un papel menos importante en las consideraciones de seguridad de este canciller ${ }^{17}$. Tampoco hubo cambios en la línea de actuación hacia España durante el gobierno de la "gran coalición" (1966-1969), caracterizándose las relaciones entre ambos países, a finales de los años sesenta, por la sintonía, el rechazo al comunismo y el continuo apoyo de la asociación española a la CEE. Por lo tanto, la llegada de los socialdemócratas alemanes al poder no supuso un cambio esencial en la estrategia de Bonn hacia Madrid. Kiesinger fue el primer canciller de la RFA en realizar un viaje oficial a España a finales de octubre de 1968 y de hecho fue el único jefe de gobierno europeo que visitó oficialmente el territorio español durante el periodo franquista ${ }^{18}$.

En el aspecto económico, el abandono de la autarquía, en gran medida gracias a la ayuda alemana, supuso el inicio de la integración de España en las instituciones económicas internacionales, desarrollando la vía del multilateralismo. A lo largo de los años sesenta y hasta 1973, España vivió su "edad dorada" económica gracias al turismo, al fuerte aumento de las exportaciones, al incremento de la inversión extranjera y a una positiva evolución del producto nacional bruto, del consumo público y del privado. A ello se sumó la absorción del excedente de mano de obra por el mercado europeo, jugando Alemania occidental también un gran papel en este ámbito ${ }^{19}$. En 1960, los gobiernos de Bonn y Madrid firmaron un acuerdo de emigración que posibilitó, a lo largo de los siguientes quince años, la salida oficial de unos 770.000 trabajadores y sus familias para trabajar en la RFA ${ }^{20}$.

Bonn esperaba beneficios de esa multilateralización dado el prestigio de los productos alemanes en España. A lo largo de todo el periodo las relaciones comerciales entre ambos países se intensificaron. Se firmaron diversos acuerdos que facilitaron el comercio bilateral y la inversión alemana en la industria española. La RFA fue en estos años el segundo comprador de sus exportaciones, mientras que realmente el significado de España como socio comercial para

17. sanz, Carlos, España y la República Federal de Alemania..., pp. 390-392.

18. "Kiesinger llega mañana", ABC, 27-X-1968; MUÑoz, Antonio, El amigo alemán. El SPD y el PSOE de la dictadura a la democracia, Barcelona, RBA Libros, 2012, pp. 21-32.

19. Sobre el desarrollo económico de España en los años sesenta véase CARRERAS, Albert y TAFUNELL, Xavier, Historia económica de la España contemporánea, Barcelona, Crítica, 2004, pp. 331-364; GIL, Alfonso J., Causas del desarrollo económico. España en Europa, 1900-2000, Madrid, Minerva, 2001, pp. 95-133; SIMÓN, Francisco, Manual de Historia económica mundial y de España, Madrid, Editorial Centro de Estudios Ramón Areces, 1991, pp. 652-653.

20. MUÑOZ, Antonio, "Una introducción a la historia de la emigración española en la República Federal de Alemania (1960-1980)", Iberoamericana: America Latina-España-Portugal, ${ }^{\circ}$ 46 (2012), pp. 23-42; SANZ, Carlos, "Illegale", "Halblegale", "Gastarbeiter". Die irreguläre Migration aus Spanien in der Bundesrepublik Deutschland im Kontext der deutsch-spanischen Beziehungen 1960-1973, Berlín, edition tranvía-Verlag Walter Frei, 2010. 
aquélla fue mucho más secundario. Sin embargo, la apuesta por la multilateralización de la economía española mereció la pena, ya que los intercambios comerciales crecieron y España experimentó un boom económico que mudó radicalmente el país y sentó las bases de la sociedad moderna y la futura democracia ${ }^{21}$.

\section{La posición de la socialdemocracia alemana hacia España}

Tras haber analizado las relaciones de los gobiernos demócrata cristianos alemanes hacia España en los años cincuenta y sesenta es necesaria una reflexión sobre la evolución del posicionamiento de la socialdemocracia alemana hacia el régimen franquista durante aquellos mismos años. A lo largo de los años cincuenta, la posición del Sozialdemokratische Partei Deutschlands (SPD) hacia la España de Franco fue de abierta y activa hostilidad. El partido no estaba dispuesto a olvidar tan fácilmente la ayuda prestada por Hitler a Franco durante la Guerra Civil. Algunos militantes e incluso dirigentes destacados (comenzando por el propio Willy Brandt) habían estado en España durante la guerra española y mantenían posiciones muy críticas hacia el régimen y sus representantes. Durante la Era Adenauer las críticas en el Bundestag del SPD al partido demócrata cristiano -Christlich-Demokratische Union Deutschlands (CDU)-, por apoyar al régimen franquista, fueron continuas, aunque sin efecto alguno en la sociedad alemana. El SPD denunció la responsabilidad de Alemania en la destrucción de la democracia española republicana y fomentó el aislamiento del régimen de las organizaciones europeas, pretendiendo con ello que el sistema franquista se colapsara y el país recuperase la democracia ${ }^{22}$.

El SPD modificó su actitud hacia la España de Franco desde mediados de los años sesenta. Tras la conversión de los socialdemócratas en un partido de masas, a raíz del congreso extraordinario de Bad Godesberg de 1959, se produjo un cambio de rumbo en sus principios de política exterior. Éste se reforzó con la llegada de Willy Brandt a la presidencia del partido en 1964, apuntalando un posicionamiento constructivo en línea con la política de distensión que el partido defendía, por aquel entonces, hacia las dictaduras comunistas. Todo ello tuvo repercusiones a medio plazo en las relaciones de la RFA con España.

Siguiendo el principio de cambio mediante acercamiento que el SPD reclamaba para la Ostpolitik y la Westpolitik, los socialdemócratas alemanes fueron modificando su radical oposición hacia la dictadura de Franco comenzando a favorecer, al igual que venía haciéndolo la $C D U$, la evolución del franquismo

21. SANZ, Carlos, España y la República Federal de Alemania..., p. 748.

22. MUÑOz, Antonio, El amigo alemán..., pp. 19-21. 
hacia la democracia y la aproximación de España a la $\mathrm{CEE}^{23}$. A mediados de los años sesenta, el SPD ya admitía las relaciones diplomáticas y comerciales de la RFA con el Estado español y apoyaba el incremento de las relaciones económicas y políticas bilaterales, si bien no se debían establecer con Madrid alianzas de otro tipo que pudieran interpretarse como una amistad hacia el gobierno de Franco ${ }^{24}$. El SPD cambió su estrategia hacia España basándose en la idea de que el aislamiento del régimen, defendido por el socialismo europeo, acabaría favoreciendo los extremismos de derecha e izquierda. Los socialdemócratas alemanes pedían un cambio en la forma de proceder para favorecer el surgimiento de una izquierda moderada en España. Con esta forma de actuar se convertían en el partido socialdemócrata europeo menos combativo con la dictadura de Franco y se mostraban consecuentes con su estrategia de distensión europea. Convergían con la línea política seguida por los gobiernos de la CDU hacia España, aunque introducían un elemento novedoso: la promoción en España del europeísmo democrático, confiando en que el incentivo de la adhesión diera preminencia a los sectores europeístas y aperturistas del régimen, allanando así el camino hacia la democracia ${ }^{25}$. También por parte española se habían producido ciertos signos aperturistas que contribuyeron al cambio en la forma de proceder del partido, como fue la promulgación en 1967 de la Ley Orgánica del Estado ${ }^{26}$.

Dentro de la amplia familia socialdemócrata alemana hubo diversidad de opiniones respecto a la línea pragmática y moderada marcada por la dirección del SPD. Especialmente a partir de finales de los años sesenta, la dirección del partido se encontró con las críticas crecientes de las juventudes (Jusos) y del gran sindicato del metal (IG Metall), por su falta de combatividad contra el franquismo ${ }^{27}$. En cualquier caso, siempre prevaleció la línea moderada marcada por Willy Brandt y la dirección del SPD, en consonancia con la distensión defendida a través de su Ostpolitik. Por ello, durante el gobierno de la "gran coalición" no se planteó ningún conflicto entre la $C D U$ y el SPD en cuanto a la forma de actuar hacia el régimen franquista.

23. Ibid., p. 67.

24. SANZ, Carlos, España y la República Federal de Alemania..., p. 485.

25. MUÑOZ, Antonio, "Europeizar es democratizar. El SPD y la España del tardofranquismo", Historia del Presente, no 17 (2011/1), p. 97.

26. Ley Orgánica del Estado num. 1/1967, de 10 de enero, en Boletín Oficial del Estado (BOE) $\mathrm{n}^{\circ}$ 9, 11-I-1967.

27. ABELSHAUSER, Werner, Nach dem Wirtschaftswunder. Die Gewerkschafter, Politiker und Unternehmer Hans Matthöfer, Bonn, Dietz, 2009, pp. 216-240. 


\section{Los vectores de la ayuda alemana a España en los años setenta}

La formación de la coalición social-liberal alemana (1969-1974) coincidió con un profundo cambio de gobierno en España. Si hasta 1969 Franco había mantenido equilibrado el poder de las diferentes familias en el gobierno, es decir fundamentalmente falangistas y opusdeistas, en el nuevo gabinete hubo una clara preponderancia de ministros tecnócratas vinculados al Opus Dei. Éstos, que habían sido los responsables de la exitosa política económica de los años sesenta, contribuyeron a relegar las sombras falangistas al pasado ${ }^{28}$.

El objetivo de este nuevo gobierno fue preparar el futuro del país sin Franco, convirtiendo la vicepresidencia, ostentada por el vicealmirante Luis Carrero Blanco desde 1967, en buena medida en una presidencia de hecho. A su vez, Franco designó a don Juan Carlos de Borbón sucesor a título de Rey, depositando a partir de entonces tanto los Estados Unidos como las grandes potencias europeas todas las esperanzas de reforma gradual democrática en el joven príncipe $^{29}$.

El canciller Willy Brandt y el ministro de Asuntos Exteriores Walter Scheel, mantuvieron hacia España la estrategia iniciada por el partido socialdemócrata desde mediados de los años sesenta. Continuaron con la "tradicional amistad" al igual que durante los gobiernos demócrata cristianos, sustentada por el buen recibimiento de las actuaciones españolas. A principios de los años setenta, España favorecía la distensión: apoyaba la normalización de las relaciones de la RFA con los países del Este, cooperaba en la preparación de la Conferencia de Helsinki y contribuía a la estabilización del Mediterráneo. La insistencia española de acercamiento a la CEE y el desarrollo económico, que desde hace años se venía produciendo en España, eran igualmente bien recibidos por el gobierno alemán. Bonn consideraba a los nuevos ministros tecnócratas moderados y europeístas capaces de protagonizar una transición democrática tras la muerte de Franco.

Willy Brandt mantuvo una postura oficial hacia el régimen de Franco, mientras que a la vez fomentó el diálogo con los antifranquistas y posibles futuros

28. MARín, José María, YSÀs, Pere y MOLInero, Carme, Historia política (1939-2000), Madrid, Istmo, 2001, pp. 187-190; PRESTON, Paul, Franco, caudillo de España, Barcelona, RBA, 2005, pp. 803-807; TUSELL, Javier, Dictadura franquista y democracia (1939-2004), Barcelona, Crítica, 2005, pp. 224-228 y 236-237.

29. Sobre el papel del Rey en el cambio democrático véase POWELL, Charles, El piloto del cambio. El rey la monarquía y la transición a la democracia, Barcelona, Planeta, 1991; POWELl, Ch., Juan Carlos. Un rey para la democracia, Barcelona, Ariel/Planeta, 1995; POWELl, Ch., El amigo americano. España y Estados Unidos: de la dictadura a la democracia, Barcelona, Galaxia Guttemberg, 2011; PRESTON, Paul, Juan Carlos: El rey de un pueblo, Barcelona, Círculo de Lectores, 2003. 
dirigentes del país. Existieron momentos de tensión entre ambos gobiernos que fueron hábilmente manejados por Bonn, bien ampliando el flujo de visitas políticas a España o, en momentos de mayor tensión, relajando las reuniones de los visitantes oficiales alemanes con la oposición ${ }^{30}$.

El canciller no visitó España durante su gestión para evitar dar una imagen de respaldo a la dictadura; sí lo hizo Walter Scheel en abril de 1970, con motivo de la concesión de un crédito alemán a España, fomentando así esa postura de apoyo al cambio mediante acercamiento ${ }^{31}$. El ministro aprovechó la visita para reunirse en casa del embajador alemán con destacados miembros de la oposición moderada y más o menos tolerada: el demócrata cristiano Joaquín Ruiz Giménez, Enrique Tierno Galván, dirigente del Partido Socialista del Interior, José María de Areilza y Joaquín Satrústegui, líder de los monárquicos democráticos, pudiendo comprobar la debilidad de estos aperturistas. Scheel fue la primera figura política europea que se entrevistaba con miembros de la oposición al régimen franquista ${ }^{32}$. Este hecho insólito fue realmente una señal táctica y motivó el malestar del gobierno español, ya que suponía legitimar por parte de Europa a la oposición política ${ }^{33}$.

Otra forma de apoyar los cambios que se estaban forjando en España fue la invitación oficial de Bonn a don Juan Carlos para visitar la RFA a finales de septiembre de 1972. El príncipe fue recibido por el canciller, el ministro de Asuntos Exteriores y el presidente de la República, Gustav Heinemann ${ }^{34}$. Con la invitación la RFA daba al príncipe el crédito que ningún otro país europeo le había dado hasta entonces, ya que estaba bastante aislado y era presentado tanto por la oposición como por la opinión pública como una "marioneta" de Franco. La amistad que se forjó tendrá un efecto muy importante en las relaciones bilaterales a partir de 1975.

La política exterior de Bonn desde mediados de los años setenta tuvo una línea de actuación innovadora: su implicación en el final de las dictaduras del sur de Europa. Como consecuencia del colapso del sistema monetario de Bretton Woods y la crisis mundial del petróleo de 1973, surgió un clima de inesta-

30. MUÑOZ, Antonio, El amigo alemán..., pp. 64-70.

31. Sobre el viaje de Scheel a España en abril de 1970: "Alemania otorgará a España un crédito de doscientos millones de marcos para las obras del trasvase Tajo-Segura", $A B C$, 24-IV-1970.

32. "Scheel traf spanische Oppositionelle", Die Zeit, 1-V-1970.

33. KNEUER, Mariane, Demokratisierung durch die EU. Süd- und Ostmitteleuropa im Vergleich, Wiesbaden, VS Verlag für Sozialwisenschaften, 2007, p. 179; ORTUÑO, Pilar, Los socialistas europeos y la transición española, Madrid, Marcial Pons, 2005, p. 193.

34. "Los príncipes han sido acogidos con medido protocolo y extrema cordialidad", $A B C$, 27-IX-1972. 
bilidad en todo el continente, que afectó especialmente a los países del sur, acabando con su prosperidad económica de los últimos veinticinco años. Tanto los EEUU como las principales potencias europeas habían confiado hasta entonces en la estabilidad política garantizada por el sistema capitalista. Una vez que ésta se quebró, un nuevo foco de preocupación surgió en el área mediterránea: el miedo a un posible avance del eurocomunismo por Europa y más concretamente sobre países inestables por el fin de sus dictaduras: Grecia, Portugal o España ${ }^{35}$. El peligro que la RFA percibía era que el eurocomunismo, tras la apariencia de una organización moderada con principios democráticos y rechazo al modelo comunista de la Unión Soviética, aspiraba a contribuir a la superación de las crisis políticas y económicas de países como Francia e Italia. Pero tras esa fachada Bonn veía el referente de Moscú. La vulnerabilidad de las democracias nacientes podía convertirse en un caldo de cultivo perfecto para el avance eurocomunista. Por esta razón, tanto el gobierno de Bonn como los partidos y fundaciones políticas alemanas buscaron desde 1974 contrarrestar el poder comunista, ayudando en los países en transición democrática a la creación de partidos políticos sólidos, tanto de derechas como de izquierdas ${ }^{36}$.

Helmut Schmidt, como canciller (1974-1982), y Hans Dietrich Genscher, como ministro de Asuntos Exteriores, continuaron con la línea establecida por Brandt de ayuda a las transiciones ibéricas y el empeño del gobierno alemán por contribuir al éxito de la implementación de las democracias. La Cancillería siguió apoyando las negociaciones españolas con la CEE. Aprovechando la confianza que el gobierno de Madrid tenía en Bonn, Schmidt se preocupó por promover el contacto entre los sectores evolucionistas del régimen y la oposición democrática, cosa de la que hasta entonces no se había preocupado ningún otro gobierno europeo ${ }^{37}$. Esa línea de actuación también se sostuvo a

35. Sobre la crisis de mediados de los años setenta en el sur de Europa véase KOHLER, Beate, Politischer Umbruch in Südeuropa. Portugal, Griechenland, Spanien auf dem Weg zur Demokratie, Bonn, Europa Union Verlag, 1981.

36. Sobre la actuación de la RFA en Portugal y España durante los procesos democratizadores véase STENGER, Matthias, Transnationale Parteienzusammenarbeit. Die Beziehungen der deutschen und portugiesischen Christlichen Demokraten von der Nelkenrevolution bis zum Vertrag von Maastricht (1974-1992), Düsseldorf, Droste, 2011; FONSECA, Ana Monica, «É Preciso Regar os Cravos!» A Social-democracia alemã e a trasição para a Democracia em Portugal (1974-1976), tesis doctoral inédita, ISCTE - Instituto Universitario de Lisboa, 2011; KAISER, Wolfram y SALM, Christian, "Transition und Europäisierung in Spanien und Portugal. Sozial- und christdemokratische Netzwerke im Übergang von der Diktatur zur parlamentarischen Demokratie", Archiv für Sozialgeschichte, no 49 (2009), pp. 259-282.

37. Durante la Cumbre de Helsinki, Schmidt intentó convencer a Arias Navarro de la necesidad de establecer un diálogo con la oposición no comunista. MUÑOz, Antonio, El amigo alemán..., pp. 204-206. 
nivel internacional ${ }^{38}$. El gobierno alemán tuvo que intensificar su apoyo a España durante la escalada de violencia de los últimos meses de 1975, intentando convencer a los países europeos de que la presión externa era contraproducente en aquellos momentos tan delicados ${ }^{39}$.

Tras la muerte de Franco, la RFA aprovechó la gran confianza que se había ganado a lo largo de los años en que había cooperado con todos los sectores, desde el mismo régimen hasta el Rey, pasando por la oposición moderada, para intentar contribuir al proceso de transición hacia la democracia. Bonn observaba la situación española bajo la óptica de los acontecimientos portugueses tras la Revolución de los Claveles y con el temor a que la deriva comunista del país vecino pudiera contagiarse a España. Por esta razón, el gobierno federal siguió muy de cerca los hechos que se iban produciendo en España, mientras que a su vez mediaba a todos los niveles (Cancillería, embajada, partidos políticos alemanes y fundaciones políticas) para conseguir una transición ordenada. Aparece por lo tanto un nuevo vector en las relaciones bilaterales de ambos países: el papel de consejero que la RFA desempeñó durante los primeros gobiernos de la transición, fomentando el diálogo con los grupos políticos demo$\operatorname{cráticos}^{40}$. A nivel internacional Alemania Occidental continuó apoyando la entrada de España en la CEE, pero supeditando la adhesión a que se dieran los pasos necesarios en favor de la democracia ${ }^{41}$.

Aun no estando exento de dudas en un principio, el apoyo al Rey fue continuo. Este espaldarazo comenzó con el aval que supuso la presencia del presidente Scheel en el acto de su coronación en noviembre de 1975 -al que no acudieron la mayoría de los Jefes de Estado europeos ${ }^{42}$ - o una nueva invitación para otra visita oficial a la RFA en abril de 1977, a dos meses de las primeras elecciones democráticas ${ }^{43}$.

38. A nivel internacional el canciller siempre se mostró partidario del acercamiento a las nuevas fuerzas emergentes y no tanto al régimen, con el objetivo de asegurar una salida democrática. A este respecto véase LEMUS, Encarnación, Estados Unidos y la Transición Española. Entre la Revolución de los Claveles y la Marcha Verde, Madrid, Silex Ediciones, 2011, p. 36; ORTUÑO, Pilar, Los socialistas europeos..., pp. 204-205; POWELL, Charles, El amigo americano..., pp. 213-214; sCHMIDT, Helmut, Hombres y poder, Barcelona, Plaza y Janes/Cambio 16, 1989, pp. 180-181.

39. MUÑoz, Antonio, Europeizar es democratizar..., p. 115.

40. NIEHUS, Gerlinde Freia, Außenpolitik im Wandel..., pp. 478-479.

41. MUÑOz, Antonio, El amigo alemán..., p. 279.

42. Además del presidente alemán, las únicas personalidades europeas de peso que estuvieron en los actos fueron el presidente francés Giscard d'Estaign, el príncipe Felipe de Edimburgo y el presidente de Irlanda Cearbhall O'Dalaig. "Todo a punto para las ceremonias de hoy", $A B C$, Madrid, 27-XI-1975.

43. Informe del Ministerio de Asuntos Exteriores alemán (Auswärtiges Amt) sobre el viaje de los Reyes a la RFA, 22-IV-1977, Politisches Archiv-Auswärtiges Amt (PAAA), Berlin, Zwischenarchiv 110249. 
Helmut Schmidt visitó Madrid a principios de 1977, seis meses después de la elección de Adolfo Suárez como presidente del Gobierno La negativa a realizar ese viaje con anterioridad, a pesar de la insistencia del presidente español, fue una forma de alentar a Suárez para que llevara a cabo las medidas reformistas. Schmidt se entrevistó con el dirigente del Partido Socialista Obrero Español (PSOE), Felipe González, además de con Suárez y don Juan Carlos de forma individual ${ }^{44}$. El canciller sugirió fórmulas para atajar la crisis económica con éxito y puso el modelo de diálogo social alemán como el ejemplo que España podía seguir; además, a esas alturas mostró ya su apoyo a la legalización del Partido Comunista de España (PCE) e insistió para que Suárez llevara a cabo la reforma sindical, con unos sindicatos moderados con los que existiera una comunicación fluida. Con ello el gobierno conseguiría limitar la gran influencia de los comunistas en el ámbito sindical ${ }^{45}$.

\section{El papel de los agentes políticos alemanes en la transición española}

Tras casi cuarenta años de dictadura en España, el alcance limitado de los partidos políticos era un gran problema para la consecución y mantenimiento de la democracia. Uno de los escasos intentos de aperturismo por parte del régimen franquista había sido la Ley de Asociaciones Políticas de 1974, cuyo objetivo era crear un sistema de asociaciones, aunque por encima se mantuviera el régimen de partido único ${ }^{46}$. Dadas sus grandes limitaciones y escaso aperturismo, el intento fracasó y la mayoría de los grupúsculos políticos se mantuvieron en la ilegalidad hasta poco antes de las elecciones generales de 1977. Sin embargo, el ambiente de apertura que comenzó a extenderse en la política española, desde poco antes de 1975, favoreció que los diferentes partidos y fundaciones políticas alemanas comenzaran a interesarse por buscar en España grupos afines a su ideología, dentro de las asociaciones y partidos políticos que se fueron formando. Su intención era ayudar al desarrollo y consolidación de un sistema partidista, sin el cual sería inviable una transición pacífica a la democracia. Ante el temor a que en España pudiera crearse una situación semejante a la de Portugal tras la Revolución de los Claveles, la colaboración de los agentes políticos alemanes tuvo una gran importancia en la creación de una clase política española capaz de llevar a buen término el proceso de democratización.

44. "Bundeskanzler Schmidt zu politischen Gesprächen in Madrid", Deutsche Presse-Agentur (dpa), 6-I-1977.

45. El embajador alemán en España, Georg von Lilienfeld, al Auswärtiges Amt, 7-I-1977, PAAA, Zwischenarchiv 115896.

46. Decreto Ley 7/1974 de 21 de diciembre por el que se aprueba el Estatuto Jurídico del Derecho de Asociación Política, en BOE nº 306, 23-XII-1974. 
Conviene explicar brevemente la naturaleza e importancia de las fundaciones políticas, agentes transnacionales característicos del sistema político alemán. Se crearon después de la Segunda Guerra Mundial como organizaciones para la educación política interna, un cometido imprescindible tras doce años de nacionalsocialismo. Están financiadas con fondos públicos, aunque utilizan el status de ONGs. Actúan en el ámbito de la RFA, pero son también muy activas en proyectos políticos internacionales. Por cada partido político existe una Fundación de ideología cercana, aunque legalmente son independientes. En las siguientes líneas se va a hacer un recorrido por la labor desarrollada por las cuatro fundaciones presentes en España durante el proceso de democratización: la Fundación Friedrich Ebert cercana al SPD, las fundaciones Konrad Adenauer y Hanns Seidel, de ideología demócrata cristiana ambas y cercanas a los partidos CDU y Chrislich-Soziale Union in Bayern (CSU) respectivamente; finalmente la Fundación liberal Friedrich Naumann, afín al Freie Demokratische Partei (FDP).

\section{El SPD y la Fundación Friedrich Ebert}

Los socialdemócratas alemanes, que ya mantenían relación con varios grupos socialistas españoles, incrementaron en 1975 sus contactos y decidieron, en el mes de abril de ese mismo año, dar su apoyo definitivo al PSOE. La obsoleta y radical dirección del partido en el exilio, la cual permanecía anclada en su rechazo completo al régimen franquista, había sido sustituida poco antes. La nueva cúpula estaba formada por una joven generación pragmática encabezada por Felipe González, cuyos objetivos eran totalmente compatibles con las ideas de los socialdemócratas alemanes. Fue decisiva la determinación que, a esas alturas, tenía el líder socialista de construir la democracia desde la monarquía y sin ruptura con el régimen anterior. Además de ello, otros dos factores contribuyeron al apoyo definitivo del SPD: el recrudecimiento de la situación en Portugal con el avance de los comunistas en el gobierno y el convencimiento de que el supuesto aperturismo del que fue el último gobierno franquista era un puro espejismo. El SPD quiso ayudar a los socialistas españoles a instaurar la democracia en España, al igual que lo estaban haciendo en Portugal. La meta final era mantener la distensión en el marco de la Guerra Fría. En los años finales del franquismo, el PCE era el grupo mejor configurado, debido a la buena organización, disciplina y capacidad de sacrificio de los cuadros comunistas, además de los amplios recursos que recibía del exterior. Por esta razón, los socialdemócratas alemanes decidieron fomentar la organización de un partido moderado de izquierda, capaz de atraer al potencial socialista español ${ }^{47}$.

47. MUÑOz, Antonio, El amigo alemán..., pp. 183-195. 
El SPD ayudó a la articulación territorial del PSOE por España y a la excarcelación de militantes socialistas. También se encargó de la formación de cuadros del partido en los valores del socialismo. Por otro lado, ayudó a lanzar a Felipe González a nivel europeo y mundial, fomentando las visitas de delegaciones socialistas europeas a España y organizando giras del líder del partido por Europa para darse a conocer. Gran parte de la ayuda del SPD al PSOE se materializó a través de la Fundación Friedrich Ebert. Su representante en España, Dieter Koniecki, abrió la oficina en Madrid a principios de 1976 y comenzó a organizar el apoyo al partido y al sindicato afín, la Unión General de Trabajadores. Para la expansión del PSOE, la Fundación alemana colaboró mediante una serie de aportaciones: la ayuda a la apertura de oficinas por todas las provincias de España; la organización de conferencias, seminarios de formación y cursos en el extranjero sobre cómo llevar a cabo campañas electorales; la creación de una línea de becas; la edición de libros informativos para los nuevos afiliados; y la ayuda a proyectos de investigación de instituciones españolas, útiles para el partido socialista ${ }^{48}$.

Con la colaboración de los socialdemócratas alemanes, los socialistas de Felipe González consiguieron las metas que se habían impuesto para las elecciones de 1977. El partido se había convertido en el punto de encuentro de la izquierda no comunista y se había consolidado como alternativa de poder frente al gobierno. A una gran distancia de los comunistas, el PSOE fue la mayor fuerza de la izquierda española. Pero faltaba aún una fuerte consolidación del partido, que se produciría en los años siguientes mediante la absorción de otros pequeños grupos socialistas, la ampliación de la base social del partido y la formación de cuadros. Para ello siguieron contando con la ayuda del SPD y de la Fundación Friedrich Ebert ${ }^{49}$.

\section{La CDU y la Fundación Konrad Adenauer}

La actuación de los agentes políticos demócrata cristianos alemanes en los procesos de transición peninsulares ha sido mucho menos estudiada que la de los socialdemócratas. Salvo para el caso portugués ${ }^{50}$, apenas existen análisis profundos sobre la implicación de la CDU y la Fundación cercana al partido, Fundación Konrad Adenauer (KAS), en las transiciones ibéricas ${ }^{51}$. Sin embar-

48. Ibid., pp. 231-277.

49. MUÑOZ, Antonio, Von der Franco-Diktatur zur Demokratie. Die Tätigkeit der FriedrichEbert-Stiftung in Spanien, Bonn, Dietz, 2013, pp. 136-214.

50. STEnger, Matthias, Transnationale Parteienzusammenarbeit...

51. Sobre las relaciones de la $C D U$ en España durante los primeros años de la transición y sobre la visión que los demócrata cristianos alemanes tenían de los acontecimientos 
go, en el caso español sí mantuvieron relación con personalidades y grupos políticos que aparentemente podrían protagonizar, tras la desaparición de Franco, un cambio político hacia la democracia. Inicialmente fueron los grupos demócrata cristianos en la oposición al régimen franquista -a su vez miembros de la Unión Europea Demócrata Cristiana desde 1965, a través del Equipo Demócrata Cristiano del Estado Español- los interlocutores principales de la CDU. Tras las elecciones de junio de 1977, los demócrata cristianos alemanes centraron su relación en el partido centrista en el gobierno, la Unión de Centro Democrático.

Un serio problema al que se tuvo que enfrentar la $C D U$ fue la gran dispersión del ámbito demócrata cristiano español. La Unión Europea Demócrata Cristiana (UEDC), heredera de los Nouvelles Equipes Internationales ${ }^{52}$, había exigido a los pequeños grupúsculos españoles su unión en un solo grupo, el Equipo Demócrata Cristiano del Estado Español (Equipo), para poder ser reconocido oficialmente como su interlocutor en España y a su vez estar éste representado en la organización europea ${ }^{53}$. El Equipo, formado en 1965, se componía de cinco grupos democristianos españoles, dos de ellos de ámbito nacional (Izquierda Democrática y Democracia Social Cristiana) y otros tres regionalistas (Partido Nacionalista Vasco, Unió Democràtica de Catalunya y Unió Democràtica del País Valencià). El empeño que pusieron los partidos integrantes de la UEDC, para conseguir que el Equipo se convirtiera en un potencial partido político fuerte y consolidado, resultó un fracaso. Esa unión, más ilusoria que real, fue un acuerdo de mínimos y pronto dejó ver las fracturas entre sus miembros, ocasionadas por el rechazo dentro del Equipo a las propuestas federalistas de catalanes y vascos, además de por el personalismo de los líderes de los partidos de ámbito nacional, José María Gil Robles y Joaquín Ruiz Giménez, dirigentes de Democracia Social Cristiana e Izquierda Democrática, respectivamente ${ }^{54}$. La actividad del Equipo quedó limitada a la represen-

españoles en aquellos años véase SARTORIUS, Nicolás y SABIO, Alberto, El final de la dictadura. La conquista de la democracia en España (noviembre de 1975-junio de 1977), Madrid, Ediciones Temas de Hoy, 2007, pp. 665-672.

52. Sobre los Nouvelles Equipes Internationales véase BECKER, Winfried, "Die Nouvelles Equipes Internationales und der Föderalismus", Historisch-Politische Mitteilungen. Archiv für Christlich-Demokratische Politik, no 15 (2008), pp. 81-102. Sobre éstos y la Unión Europea Demócrata Cristiana véase JANSEN, Thomas, Die Entstehung einer Europäischen Partei. Vorgeschichte, Gründung und Entwicklung der EVP. Bonn, Europa Union Verlag, 1996; PAPINI, Roberto, La internacional Demócrata Cristiana, Caracas, IFEDEC, Centro Internacional de Formación "Arístides Calvani”, 1986.

53. BARBA, Donato, La oposición durante el franquismo. La democracia cristiana, Madrid, Encuentro, 2001, p. 129.

54. UEDC/EUCD, Procès-verbal de la reunión du bureau, Rome, 17-XII-1966, Archiv für christlich-demokratische Politik (ACDP) 09-004-030. 
tación conjunta de la democracia cristiana española en los organismos y reuniones internacionales, ya que dentro de España fue muy escasa ${ }^{55}$.

Siendo consecuente con la línea seguida por la Unión Europea Demócrata Cristiana, la $C D U$, a pesar de lo confuso del espectro político del centro derecha español, mantuvo como interlocutor oficial al Equipo desde $1974^{56}$. La relación de los demócrata cristianos alemanes con los partidos afines en España se mantuvo fundamentalmente a través de la KAS, que si bien no abrió su delegación en España hasta octubre de 1976, había comenzado a interesarse por la situación española desde mediados de 1975. Josef Thesing, responsable del área de solidaridad internacional, fue el encargado del proyecto español ${ }^{57}$. Los intereses de la Fundación en España fueron principalmente dos: favorecer la democratización del país con fuerzas democráticas españolas, evitando así la continuidad del franquismo sin Franco y fomentar la entrada de España en la CEE ${ }^{58}$.

En septiembre de 1975 Thesing realizó su primer viaje a España como representante de la Fundación Konrad Adenauer. Tenía clara la idea de que para poder llevar a cabo la democratización era absolutamente necesario contar con personas que no hubieran pertenecido al régimen franquista. Con anterioridad a este primer viaje, en junio de 1975, ya había estado reunido en Bonn con uno de los miembros de Izquierda Democrática, Íñigo Cavero, habiendo elaborado un programa de trabajo conjunto para los partidos del Equipo y la Fundación ${ }^{59}$.

Los objetivos del viaje de Thesing eran dos: concretar definitivamente con los grupos demócrata cristianos españoles la posibilidad de que la Fundación

55. BARBA, Donato, La oposición durante el franquismo..., p. 215.

56. NIEHUS, Gerlinde Freia, Außenpolitik im Wandel..., p. 515.

57. En 1961 se creó en la RFA el Ministerio de Cooperación Económica con los países en vías de desarrollo (Bundesministerium für wirtschaftliche Zusammenarbeit und Entwicklung - BMZ-). En paralelo la KAS creó - en julio de 1962 - su propio Instituto de solidaridad internacional, el Institut für Internationale Solidarität. A través de esta entidad la Fundación canaliza las ayudas recibidas del ministerio y desarrolla los contactos con partidos demócrata cristianos, sindicatos y otras instituciones en los países en vías de desarrollo. La idea general es ayudar a quienes lo necesitan, bajo las premisas de un entendimiento cristiano de los derechos humanos, democracia y justicia social. Sobre el trabajo que se desarrolla a través del Institut für Internationale Solidarität véase THESING, Josef, "Die Konrad-Adenauer-Stiftung in der Welt. Der Beginn der Arbeit des Instituts für Internationale Solidarität", Historisch-Politische Mitteilungen. Archiv für Christlich-Demokratische Politik, no 19 (2012), pp. 305-318; THESING, J. (coord.), In der Welt und für die Welt. 40 Jahre internationale Zusammenarbeit, Sankt Augustin, KonradAdenauer-Stiftung, 2002.

58. Entrevista personal con Josef Thesing, Sankt Augustin, 31-X-2012.

59. Informe de Josef Thesing sobre su viaje a Madrid del 7 al 10 de septiembre de 1975, Institut für Internationale Solidarität der Konrad-Adenauer-Stiftung e.V., en Sankt Augustin (Bonn), ACDP 12-001-1261. 
colaborara con ellos y la preparación de un proyecto de trabajo conjunto. A lo largo de tres días se entrevistó con varios miembros de Izquierda Democrática y de Federación Popular Democrática (anteriormente Democracia Social Cristiana). Los grupos regionalistas estuvieron representados por los anteriores. Las conversaciones que el representante alemán mantuvo con los integrantes de la democracia cristiana española dieron su fruto, puesto que a partir de entonces comenzó a materializarse la ayuda de la KAS para la creación de un sólido partido demócrata cristiano de carácter federativo ${ }^{60}$.

La Fundación demócrata cristiana alemana comenzó a colaborar en la organización de actividades de formación política a través del Instituto de Investigación Socio-Política (INDESP), creado en septiembre de 1975 en el seno de la Fundación Universitaria San Pablo y concebido como centro de formación política para el Equipo. Por otra parte, la KAS también organizó seminarios y conferencias en su academia de Eichholz para los miembros de los diferentes partidos del Equipo ${ }^{61}$.

A finales de 1976, la Fundación encargó a la empresa DATA, presidida por el sociólogo y politólogo español Juan Linz, la realización de un sondeo de opinión pública muy extenso sobre la realidad política del momento y la intención de voto en España ${ }^{62}$. Uno de los mayores problemas que observaba Josef Thesing era la falta de conocimiento de los miembros del Equipo sobre el comportamiento político de los españoles. Por ello era necesario mentalizar a los cinco partidos demócrata cristianos de las necesidades y voluntad de la sociedad española, antes de las elecciones de junio. Los resultados de dicho sondeo, basado en 8.837 entrevistas, se presentaron en enero de 1977: la mayoría de los españoles querían la democracia, pero rechazaban cualquier política radical y cualquier tipo de experimento en sentido revolucionario. La época de Franco había pasado aunque, en general, la gente valoraba los beneficios de la reconstrucción económica que se había producido. Especialmente la fuerte clase media, que era la mayor beneficiada del desarrollo económico a todos los niveles, no quería correr ningún riesgo político. Nuevas caras como la de Adolfo Suárez imprimían un nuevo estilo político con el que se identificaban muchos españoles. Con estas premisas se llegó a la conclusión de que, únicamente, un partido de centro sería capaz de ganar las primeras elecciones democráticas. Aun presentando estos datos tan relevantes y realizando un gran esfuerzo a todos

60. Ibid.

61. Informe personal de Josef Thesing para Bruno Heck (presidente de la KAS), 21-VI-1976, ACDP 12-001-1261.

62. Informe confidencial de Josef Thesing para Helmut Kohl, presidente de la CDU (19731998), sobre el desarrollo político en España, 10-V-1977, archivo privado de Josef Thesing. 
los niveles, la Fundación Konrad Adenauer no fue capaz de convencer a Gil Robles y Ruiz Giménez de la necesidad de incorporar al Equipo a un gran partido de centro. Fundamentalmente, fue el primero quien no quiso juntarse con políticos que hubieran tenido algo que ver con el régimen franquista. El resto de los componentes regionalistas del Equipo no tuvieron la fuerza suficiente para cambiar la decisión de los dos anteriores ${ }^{63}$.

En primavera de 1977, Izquierda Democrática y la Federación Popular Democrática se unieron en la Federación de la Democracia Cristiana y juntas se presentaron a las elecciones generales de junio. Los resultados fueron desastrosos, obteniendo solamente un 1,18\% de los votos y ninguna representación parlamentaria ${ }^{64}$.

Puede por lo tanto afirmarse que en España los democristianos estuvieron perfectamente identificados desde el inicio de la transición, a diferencia del caso portugués, donde la democracia cristiana alemana tuvo serios problemas para identificar a un interlocutor de ideología afín, dado que no existía ningún grupo de ese país representado en la UEDC cuando se produjo la Revolución de los Claveles. El fracaso de los españoles en las primeras elecciones democráticas se debió, fundamentalmente, a la ineficacia de los líderes de la Federación de la Democracia Cristiana, que no tuvieron la amplitud de miras suficiente para comprender lo que realmente quería y necesitaba el pueblo español tras cuarenta años de régimen dictatorial, e hicieron prevalecer sus propios intereses. La Fundación Konrad Adenauer, desde principios de 1977 y con los resultados del sondeo en la mano, había predicho con acierto la voluntad de los españoles y había recomendado insistentemente a los demócrata cristianos su integración en una formación centrista. Por lo tanto la Fundación había realizado un buen análisis político de la situación española. De hecho, de los interlocutores habituales de la KAS hubo un grupo, liderado por Fernando Álvarez de Miranda $^{65}$, que se había escindido de Izquierda Democrática en primavera de 1976 y había creado el Partido Demócrata Cristiano. Este grupo sí aceptó los

63. Ibid.

64. Informe de Josef Thesing "Die Wahlen in Spanien", IIS-Info Auslandsinformationen, 4VII-1977.

65. Fernando Álvarez de Miranda había formado parte del grupo de Gil Robles hasta 1964 y posteriormente de Izquierda Democrática hasta abril de 1976, momento en que se decide el ingreso del partido en Coordinación Democrática. Este organismo, que exigía al gobierno una serie de medidas democráticas, estaba formado por varios partidos políticos entre ellos el PCE. Por esta razón se produjo la escisión de un grupo de políticos, encabezado por Álvarez de Miranda, que crearon el Partido Demócrata Cristiano. Véase ÁlVAREZ DE MIRANDA, Fernando, Del contubernio al consenso, Barcelona, Planeta, 1985; ÁlVAREZ De miranda, F, La España que soñé. Recuerdos de un hombre de consenso, Madrid, La Esfera de los Libros, 2013. 
consejos de la Fundación ${ }^{66}$. El partido de Álvarez de Miranda se integró en Unión de Centro Democrático (UCD), conglomerado de quince partidos muy heterogéneo -en su seno había grupos políticos que iban desde la socialdemocracia hasta los demócrata cristianos, pasando por los liberales- que se había creado pocos meses antes de las elecciones generales. UCD, un partido de centro con apenas tres meses de vida, ganó las primeras elecciones democráticas consiguiendo 165 escaños para el Congreso de los Diputados, de los cuales 34 estuvieron ocupados por el grupo demócrata cristiano de Álvarez de Miranda ${ }^{67}$. ¿Se puede realmente hablar de un fracaso del trabajo de la Fundación Konrad Adenauer en España?

Tras las históricas elecciones generales de junio de 1977, que supusieron la derrota de Gil Robles y Ruiz Giménez, la Fundación Konrad Adenauer decidió centrar su apoyo en la Unión de Centro Democrático, intentando fomentar a su sector demócrata cristiano y ayudando a su fortalecimiento ${ }^{68}$. La contribución de la democracia cristiana alemana comenzó a materializarse pocos meses después de las elecciones, a principios de octubre de 1977, con la organización de un seminario para cuarenta dirigentes de Unión de Centro Democrático, sin distinción de sus ideologías políticas ${ }^{69}$. A finales de año la Fundación ayudó a los democristianos integrados en el partido, Iñigo Cavero, Oscar Alzaga y Fernando Álvarez de Miranda, a crear la Fundación Humanismo y Democracia, diseñada para la formación política de los militantes de Unión de Centro Democrático y por lo tanto para ampliar la ideología demócrata cristiana en el seno del partido ${ }^{70}$. La Fundación Konrad Adenauer también estuvo en contacto con los principales redactores de la Constitución de 1978, basada en muchos aspectos en la Ley Fundamental alemana de 1949. Varios miembros de la Comisión Constitucional del Congreso viajaron a la sede de la Fundación en Bonn, donde se organizaron encuentros con profesores alemanes de derecho constitucional ${ }^{71}$.

66. En una entrevista personal con Fernando Álvarez de Miranda el 14-II-2013, éste reconoce agradecido la gran ayuda de la Fundación Konrad Adenauer y la CDU durante la transición española. 67. <http://www.juntaelectoralcentral.es/portal/page/portal/Junta ElectoralCentral/JuntaElectoralCentral/ResultElect/ElGeneral/15Junio1977> (Consultado el 21-I-2014).

68. Carta de Henning Wegener, director del Departamento de Relaciones Internacionales de la CDU a Karl Carstens, presidente del Bundestag, 11-XI-1977, ACPD 07-001-16009.

69. Informe del Departamento de Relaciones Internacionales de la CDU para Helmut Kohl: Reunión del Präsidium del 17-X-1977; puntos fuertes y problemas del trabajo internacional de la CDU, 12-X-1977, ACDP 07-001-16026.

70. ÁlVAREZ de miranda, Fernando, Del contubernio..., p. 142.

71. Entrevista personal con Josef Thesing, Sankt Augustin, 31-X-2012. 
Durante la transición, la Fundación invitó a destacados intelectuales, políticos y periodistas españoles a viajar a la RFA, en gran medida por razones psicológicas. Su intención era eliminar de las mentes españolas la sensación de aislacionismo y mostrar el pensamiento abierto alemán. Por ello, el abanico de invitados no sólo se limitó a gente de ideología demócrata cristiana ${ }^{72}$. A su vez, la Fundación Konrad Adenauer realizó un gran esfuerzo para convencer a los políticos españoles de finales de los años setenta de la necesidad de que España entrara a formar parte de la OTAN, ya que por aquella época todavía era necesario combatir las reticencias españolas hacia la Alianza Atlántica ${ }^{73}$.

Hasta su disolución en febrero de 1983, la Unión de Centro Democrático contó con el fiel apoyo de la CDU. Se trataba de ampliar el sector demócrata cristiano en su seno y finalmente poder integrar al partido en la UEDC y en el Partido Popular Europeo, una vez que España entrara a formar parte de la CEE. Sin embargo, esto no fue posible al fracasar el proyecto de Unión de Centro Democrático ${ }^{74}$. Tras un apoyo inicial de la CDU al nuevo partido demócrata cristiano creado por Oscar Alzaga en 1982, el Partido Demócrata Popular (PDP), avanzados los años ochenta acabará siendo Alianza Popular (después Partido Popular) el partner español de la CDU.

\section{La CSU y la Fundación Hanns Seidel}

Existía a finales de 1975 otra fuerza política que se consideraba a si misma demócrata cristiana y que se había formado en el marco de la Ley de Asociaciones Políticas de diciembre de 1974, la Unión Democrática Española. Su líder Federico Silva Muñoz, había sido Ministro de Obras Públicas durante el franquismo. El partido estaba dispuesto a trabajar en conjunto con los demócrata cristianos de la oposición y en concreto con los dos grupos de ámbito nacional, Izquierda Democrática y Federación Popular Democrática. Como uno de sus objetivos era la realización de una política centralizada, no contemplaba la colaboración con los partidos vascos y catalanes ${ }^{75}$. De cualquier manera, ninguno de los líderes del Equipo, al igual que otros partidos integrantes de la Unión Europea Demócrata Cristiana, estaban dispuestos a trabajar con un partido cuyo líder había colaborado con el régimen franquista ${ }^{76}$.

72. Sirva como ejemplo la invitación a Bonn de doce periodistas de diversos rotativos españoles en enero de 1976. Archivo privado de Josef Thesing.

73. Entrevista personal con Josef Thesing, Sankt Augustin, 31-X-2012.

74. Huneeus, Carlos, La Unión de Centro Democrático y la transición a la democracia en España, Madrid, Centro de Investigaciones Sociológicas, 1985.

75. SILVA, Federico, Memorias políticas, Barcelona, Planeta, 1993.

76. Informe de Klaus Weigelt, representante de la KAS en Venezuela entre 1975-1981, tras una estancia en España de tres meses (6-IV-1975 al 6-VII-1975), ACDP 12-001-1261. 
La relación de Unión Democrática Española con el partido demócrata cristiano bávaro era estrecha, en buena parte debido a la larga amistad de Silva Muñoz con Franz Josef Strauss (dirigente de los bávaros desde 1961). A la altura de diciembre de 1975 la Fundación Hanns Seidel, cercana a la CSU, ya contemplaba la realización de programas políticos para la asociación española, en paralelo o como contraste a los que la Fundación Konrad Adenauer estaba preparando con los miembros del Equipo ${ }^{77}$.

La Fundación Hanns Seidel abrió su oficina de representación en España en 1977 y colaboró en la creación del nuevo espectro político. La Fundación apoyó en las elecciones de 1977 a Alianza Popular (AP), partido político que había creado en octubre de 1976 el exministro de Gobernación Manuel Fraga Iribarne $^{78}$. AP integraba a siete grupos políticos (incluido el partido de Silva Muñoz), cuyos dirigentes habían sido en su mayoría afamados ministros franquistas $^{79}$. Fraga, que hasta entonces se había declarado centrista, daba un giro hacia la derecha y aunaba así bajo un único partido a las fuerzas más reacias al cambio, para poderlas controlar y convertir en una "derecha civilizada". La Fundación Hanns Seidel ayudó a la creación del Instituto de Estudios Sociales (IESO), centro de formación política de AP, que organizaba encuentros con periodistas, seminarios para mujeres y diversos cursos de índole política para simpatizantes del partido ${ }^{80}$.

A pesar de los malos resultados de Alianza Popular en las elecciones de 1977 y $1979^{81}$, la Fundación Hanns Seidel mantuvo su apoyo a su partner español durante los siguientes años. Muchos de los seminarios que se organizaron a través de la Fundación Cánovas del Castillo -creada en los años ochenta en el seno del partido-, tuvieron como objetivo dividir a la Unión de Centro Democrático, con el fin de captar para AP tanto votos como nuevos miembros ${ }^{82}$.

77. Informe de Heinrich Böx respecto un sondeo realizado en España sobre la situación política, entre el 8 y 10 de diciembre de 1975, ACDP 12-001-1261.

78. "Eine neue Partei stellt sich in Madrid vor", Die Welt, 10-XI-1976.

79. Los partidos políticos que se integraron en Alianza Popular fueron los siguientes: Reforma Democrática (liderada por Manuel Fraga), Unión del Pueblo Español (Cruz Martínez Esteruelas), Democracia Social (Licinio de la Fuente), Acción Regional (Laureano López Rodó), Unión Social Popular (Enrique Thomas de Carranza), Unión Nacional Española (Gonzalo Fernández de la Mora) y Acción Democrática Española (anteriormente Unión Democrática Española liderada por Federico Silva Muñoz).

80. Mager, Friedrich y mauter, Paul, Stiftungen im Dienst der Politik. Am Beispiel Spanien, Bayerischen Rundfunks, República Federal de Alemania, 12 de Julio de 1977.

81. En las elecciones de 1977 Alianza Popular sólo logró un 8\% de los votos y 16 escaños, mientras que en las elecciones generales de 1979 el porcentaje de votos se redujo al 6\% y su representación en el Congreso a 9 diputados.

82. NIEHUS, Gerlinde Freia, Außenpolitik im Wandel..., p. 521. 


\section{El FDP y la Fundación Friedrich Naumann}

En palabras de su representante en Madrid, Fritz E. Steinberg, la Fundación Friedrich Naumann tuvo poco que celebrar respecto al objetivo de fomentar un partido liberal en la transición española. Sin embargo, hay que tener muy en cuenta el punto de partida. Era prácticamente imposible conseguir la creación de un partido de ideología liberal en España, donde el liberalismo arrastraba una percepción negativa desde el inicio del siglo, la cual el franquismo se había encargado de desacreditar. A pesar de ello existía una gran variedad de organizaciones, clubs y grupos liberales ${ }^{83}$.

A finales de 1975, uno de analistas políticos de la embajada alemana informó a los líderes del FDP en Bonn del interés que habían mostrado varios españoles, al acudir a la embajada para interesarse por la ideología liberal. Tras un viaje a Bonn de varios representantes de los grupos liberales españoles, durante el cual se reunieron con miembros de la Fundación Friedrich Naumann, ésta decidió proceder a la apertura de una delegación en Madrid en julio de 1976, si bien ya existían contactos, desde poco antes de la muerte de Franco, entre los liberales alemanes y españoles en el marco de las organizaciones liberales internacionales ${ }^{84}$.

Steinberg se encontró con un amplio espectro de pequeños grupos, la mayoría de los cuales no estaban dispuestos a cooperar entre ellos. El contacto más importante de la Fundación Friedrich Naumann fue el grupo liberal del político Joaquín Garrigues Walker, aunque también apoyaron a otros grupos como los regionalistas Esquerra Republicana de Catalunya o Esquerra Democràtica de Catalunya. En concreto, estos dos partidos catalanes fueron integrados en la Internacional Liberal gracias a la intercesión del partido liberal alemán ${ }^{85}$. En 1976, la Fundación organizó once seminarios, dos de ellos en la RFA y el resto en Madrid, Barcelona y Bilbao. Los primeros informes de Steinberg reflejaban una: la carencia de estructuras organizativas de los grupos liberales y la negativa de éstos a unirse en un solo partido. Otro de los problemas con el que se encontró el representante de la Fundación fue el choque cultural español con el procedimiento administrativo del sistema alemán: retra-

83. BORGER, Sebastian, Germany's party political foundations in Spain: a case-study of quasiofficial foreign policy, Londres, 1998, inédito, p. 20.

84. Solicitud de la Fundación Friedrich Naumann al Bundesministerium für wirtschaftliche Zusammenarbeit und Entwicklung del 19-III-1976 para la apertura de una delegación en Madrid, Bundesarchiv, Coblenza, B213-21277.

85. "Bruselas: la Internacional Liberal ratifica su deseo de democratización para España", La Vanguardia, 2-X-1976; "Los liberales deberán prestar una ayuda especial a España", Ya, 3-X-1976. 
sos, recibos mal presentados o liquidaciones de cuentas que no cumplían las normas contables ${ }^{86}$.

Antes de las elecciones de 1977, la mayoría de los interlocutores españoles de la Fundación decidieron unirse a Unión de Centro Democrático, una decisión recomendada por el Ministro de Exteriores alemán, Hans Dietrich Genscher, ante la ausencia en España de un partido liberal fuertemente consolidado. La muerte prematura de Joaquín Garrigues en 1980 y la disolución de UCD supusieron temporalmente el fin de la influencia de la Fundación liberal alemana en España. No obstante, al haber estimulado a los partidos regionales, la Fundación Friedrich Naumann ayudó a exportar a nivel regional el sistema federalista de administración alemán ${ }^{87}$.

\section{Conclusión}

El análisis de la evolución de la política exterior de la RFA hacia España a lo largo de sus primeros treinta años de existencia permite extraer tres conclusiones fundamentales. La primera y más extendida es la necesidad de adecuación de la política exterior de una nueva democracia hacia una dictadura, con el agravante de que la nueva república federal se constituía sobre las ruinas de un régimen del que esa dictadura había sido un gran amigo. Que además estas relaciones se encontraran enmarcadas dentro del contexto general de la Guerra Fría y del periodo de reconstrucción de postguerras y conformación del proyecto europeo, determinó un acicate especial para la superación de las diferencias ideológicas.

El segundo vector está constituido por la positiva evolución de las relaciones bilaterales hispano-alemanas durante los primeros veinticinco años de existencia de la RFA; lo que fue determinante para que, a mediados de los años setenta, ésta se convirtiera en un gran apoyo para la España que comenzaba su andadura democrática. En los años cincuenta España jugó un papel secundario en la política exterior de la RFA, al tener Alemania occidental otras prioridades post-bélicas más urgentes. No obstante esta década sirvió para reestablecer las bases de la amistad entre ambos países. Las relaciones se intensificaron a lo largo de los años sesenta, en los que la RFA se convirtió definitivamente en un gigante económico y España comenzó a disfrutar de los beneficios de su salida de la autarquía, experimentando una gran recuperación económica. El gobierno de Bonn apoyó en todo momento a España y su solicitud de adhesión a la CEE ya que, siguiendo su férrea Westpolitik de los años setenta,

86. BORGER, Sebastian, Germany's party political ..., p. 21.

87. Ibid., p. 22. 
veía en el europeísmo español la solución para la democratización del país a la muerte de Franco. En ese aspecto, tanto la CDU como el SPD, a diferencia de otros partidos políticos europeos, habían entendido con acierto que el aislamiento europeo del régimen franquista no era positivo y podría acabar favoreciendo la aparición de extremismos de derecha e izquierda.

El tercer vector a tener presente lo conforman las actuaciones paraoficiales de las fundaciones políticas germanas. En todo el proceso de transición democrática jugaron un papel muy importante que ha sido valorado por la historiografía de forma muy positiva como ejemplo de éxito de la labor de dichos agentes políticos en su actividad transnacional. En el caso español, el esfuerzo realizado por las fundaciones no se debió a un plan preconcebido para la democratización del país. Su actividad estuvo más bien encaminada a llevar a cabo con discreción una serie de acciones concretas, en un momento decisivo de la transición, para facilitar la actividad de los partidos políticos. Sin embargo, la dimensión de la labor realizada por estos actores con el objetivo de crear una alternativa política real tras cuarenta años de dictadura franquista, todavía no ha sido suficientemente investigada y valorada, salvo en el caso de los socialdemócratas alemanes y el PSOE. 